\title{
Sartículos
}

\section{Las restauraciones de la Catedral de Málaga en la época de la Autarquía (II)}

\author{
Javier Ordóñez Vergara
}

Universidad de Málaga

RESUMEN

Recorrido cronológico y por sectores a través de los proyectos de restauración desarrollados durante las dos décadas posteriores a la guerra civil en el conjunto catedralicio de Málaga, abordando en esta primera parte del artículo el recinto de la catedral nueva. Se avanzan algunas de las conclusiones acerca de lo que dichas obras supusieron en la conformación del monumento y, por extensión, en la interpretación de las pautas que caracterizaron la intervención en la arquitectura histórica durante la primera mitad del período franquista.

PALABRAS CLAVE: Restauración / Arquitectura / Franquismo / España.

Restorations in Catedral of Málaga during “Autarquía” times.

ABSTRACT

Chronological and sectorial run through the projects of restoration, developed during the two decades after the end of Spanish Civil War in the Cathedral complex of Málaga, including, in this first part of the article, the premises of the new cathedral. Conclusions are broached, about the influence that such works had in the configuration of the monument itself, as well as, in the different theories about the aims and characteristics of the restoration work of the historical architecture during the first part of Franco's Regime.

KEY WORDS: Restoration/ Architecture/ Franco's Regime/ Spain.

\section{INTRODUCCIÓN}

La problemática de la restauración monumental en los años de la posguerra española ha sido tratada habitualmente desde la perspectiva de la actuación de los diversos organismos responsables de la misma. Entre los principales autores destaca A. Muñoz Cosme, cuyos trabajos analizan desde una perspectiva global la evolución del pensamiento y el tratamiento conservativo que ha caracterizado la arquitectura histórica y su contexto durante la contemporaneidad ${ }^{2}$. A grandes rasgos, su conclusión es que durante el período de autarquía coexisten dos líneas fundamentales de actuación que darán lugar a intervenciones de variado signo: una más atenta a las

* ORDÓÑEZ VERGARA, Javier: "Las restauraciones de la Catedral de Málaga en la época de la Autarquía (I)", en Boletín de Arte, $\mathrm{n}^{\circ}$ 29, Departamento de Historia del Arte, Universidad de Málaga, 2008, págs. 421-436.

1 Este trabajo se realiza en el marco del proyecto de investigación"RECONSTRUCCIÓN Y RESTAURACION MONUMENTAL EN ESPAÑA 1938-1958. LAS DIRECCIONES GENERALES DE REGIONES DEVASTADAS Y DE BELLAS ARTES", ref.:HUM2007-62699. La segunda parte de este artículo aparecerá publicada en el $n^{\circ} 32$ de la revista Baetica, Estudios de Arte, Geografía e Historia, Facultad de $F^{a}$ y Letras, Universidad de Málaga. 
necesidades reales de reparación y consolidación de los monumentos que enlaza con la tradición de la restauración científica, implantada en determinados ámbitos a lo largo del primer tercio del s. XX; y otra que retoma algunas de las características que habían sido propias de la llamada escuela restauradora, defensora de una postura más decidida a la hora de determinar arbitrariamente el estado y aspecto ulterior de los monumentos, con actuaciones grandilocuentes, poco rigurosas desde el punto de vista histórico y que no se ajustan a un criterio constante. Aunque esta segunda tendencia identifica a la mayor parte de las actuaciones promovidas por el Servicio -luego Dirección- General de Regiones Devastadas y Reparaciones ${ }^{3}$ (a la que a partir de ahora nos referiremos como DGRRDD) del Ministerio de la Gobernación, así como, en mucha menor medida durante estas primeras décadas del Franquismo, por la Dirección General de Arquitectura ${ }^{4}$, también dependiente de la Gobernación y luego del Ministerio de la Vivienda desde su creación en 19575. Dicha línea de actuación es perceptible también -junto con la primera- en la labor que realizan organismos como la Comisaría -luego Servicio- de Defensa del Patrimonio Artístico Nacional ${ }^{6}$, dependiente de la Jefatura Nacional de Bellas Artes y más tarde Dirección General de Bellas Artes (en adelante DGBBAA) del Ministerio de Educación Nacional. Dicho organismo, responsable principal de la vigilancia de los monumentos así declarados, emprendió numerosas actuaciones que tuvieron que resolverse generalmente con serias limitaciones debidas a múltiples factores, entre los que destacan la cantidad ingente de edificios que atender, la magnitud de los daños que éstos presentaban (agravado muchas veces por la guerra y el vandalismo ejercido durante su trascurso y con anterioridad al conflicto), la urgencia por rehabilitar las funciones que los inmuebles venían desempeñando o por adaptarlos a nuevas necesidades, además de la penuria económica y de medios propia del momento, sin olvidar tampoco la irregular formación histórica, así como los intereses y prioridades de aquellos que promueven tales planes, diseñan los proyectos o ejecutan las obras.

Por otra parte, en el caso de los monumentos de carácter religioso en el ámbito de la diócesis de Málaga, no se aprecia diferente orientación en función de quienes ocupan el obispado durante este período (Santos Oliveira -denominado "obispo de la reconstrucción"- y Herrera Oria, respectivamente antes y después de octubre de $1947^{7}$ ) dada la continuidad administrativa en la política de restauración, de sus

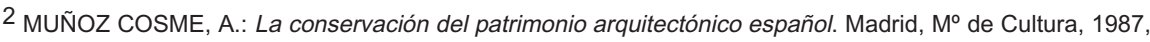
cap. III “La época de la reconstrucción”, págs. 111-143.

3 Decreto de 25 de marzo de 1938.

4 Ley de 23 de septiembre de 1939.

5 LÓPEZ DÍAZ, J.: "Vivienda social y Falange: ideario y construcciones en la década de los 40", Scripta Nova n 146, 2003, pág. 2. La DGA acabará asumiendo definitivamente una parte de las competencias de la extinta DGRRDD.

6 Decreto de 22 de abril de 1938.

7 MATEO AVILÉS, E. de (coord.): La vida y obra del Cardenal Herrera Oria. Estudios, testimonios, documentos e imágenes. Málaga, Ayuntamiento, 2006, pág. 14.
} 


\section{- artículos Las restauraciones en la Catedral de Málaga...}

responsables y de los técnicos que intervienen.

La investigación del proceso de intervención en un conjunto como la Catedral de Málaga (incluida la iglesia del Sagrario, a la que desde su origen ha estado vinculada) durante las dos décadas posteriores a la guerra civil, no solo tiene interés desde el objetivo de documentar unas obras llevadas a cabo durante este periodo de modo que consigan enriquecer y aclarar el origen de parte de su configuración actual, sino también desde la perspectiva de lo representativas que éstas puedan resultar en relación al tratamiento que entonces se da a buena parte del acervo monumental.

\section{La Catedral.}

Una vez acometidos los trabajos más urgentes de "limpieza y adecentamiento" llevados a cabo a partir de la entrada de los nacionales en la ciudad a principios de febrero de $1937^{8}$ para hacer frente a los daños ocasionados en el interior del templo a consecuencia de los asaltos de julio de $1936^{9}$ y a su ocupación desde entonces por parte de grupos de refugiados ${ }^{10}$ [1], se emprendieron una serie de proyectos de reparación y restauración que, en su mayor parte y como corresponde a la condición que como monumento detenta desde su declaración ${ }^{11}$, son programados y financiados fundamentalmente por la DGBBAA desde la jefatura del Servicio de Defensa del Patrimonio Artístico Nacional de la $7^{\mathrm{a}}$ zona, que abarca el sudeste peninsular, si bien en muchas ocasiones tanto el diseño de los proyectos como la dirección técnica de los mismos serán responsabilidad del arquitecto diocesano ${ }^{12}$. El artículo primero del Decreto de 9.3.1940 establecía que el Estado podría tomar a su cargo -íntegramente y de acuerdo con la jerarquía eclesiástica- las obras de reparación en catedrales, palacios episcopales y seminarios ${ }^{13}$, del mismo modo que ya se

8 BARRANQUERO TEXEIRA, E.: Málaga entre la guerra y la posguerra. El franquismo. Málaga, Arguval, 1994, pág. 174-175: acordados en el cabildo de 19.2.1937, coordinados por la junta Pro-Catedral, y sufragados por suscripción popular y por el ayuntamiento de la ciudad.

9 Archivo Histórico Provincial de Málaga (AHPM): legajo 13935, carpeta 4.9. MATEO AVILÉS, E. de: Las víctimas del Frente Popular en Málaga. La "otra" memoria histórica. Málaga, Arguval, 2007, pág. 60. En NADAL SÁNCHEZ, A.: Guerra Civil en Málaga. Málaga, Arguval, 1984, pág. 232 se reproduce una fotografía de la época con el pié "Milicianos presos salen de la catedral donde proceden a su arreglo".

10 MORALES FOLGUERA, J.M.: "Las sombras de la memoria. Apuntes sobre dos siglos del Patrimonio Histórico de la Iglesia malagueña. Siglos XIX y XX”, en SÁNCHEZ-LAFUENTE GÉMAR, R.: El esplendor de la memoria. El arte de la Iglesia de Málaga. Málaga, Junta de Andalucía y Obispado de Málaga, 1998, págs. 62-67 (66); SAURET GUERRERO, T. La catedral de Málaga. Málaga, Diputación Provincial, 2003, págs. 130-131.

11 Decreto de 3.6.1931, Gaceta de Madrid nº 155, 4.6.1931, págs. 1174-1185.

12 La razón de este reparto de tareas se encuentra por lo general en que la oficina del arquitecto diocesano, impulsora de la intervención en primera instancia, para su aprobación y financiación recurre necesariamente al arquitecto conservador de zona -que a veces rehace el proyecto o simplemente lo hace suyo-, ejecutando éste el plan mediante el sistema de administración directa, puesto que al contar con su propia infraestructura y medios auxiliares ello suponía un ahorro considerable (ca. $20 \%$ ) en la inversión publica a efectuar.

13 Archivo General de la Administración (AGA), Alcalá de Henares: fondo (04) 78, signatura 26/16194. 


\section{Q: artículos Javier Ordóné Vergara}

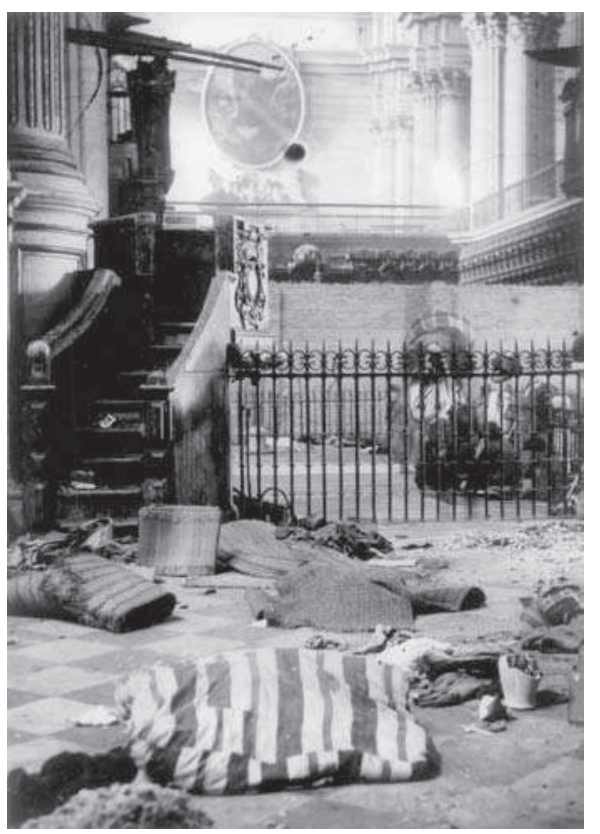

1. Aspecto del interior de la catedral en 1937. Archivo Temboury (AT): foto $n^{\circ}$ 3400 .

hacía por parte de la DGRRDD con las construcciones de localidades adoptadas por el Caudillo ${ }^{14}$, según expresión oficial.

En general, las intervenciones que se verifican a partir de entonces y hasta el final de la década de los ' 50 en el conjunto de inmuebles que integran el complejo catedralicio, componen un proceso marcado por la intermitencia, con iniciativas diferidas en el tiempo respecto al momento en que se acusan o reconocen los daños, y dirigidas principalmente a la realización de labores de conservación. Su impulso reconstructor resulta por tanto muy limitado, evidenciando así una orientación netamente diferenciada respecto a otras iniciativas de la época promovidas por otros organismos con los que suele asociarse el fenómeno de la restauración de posguerra, como es el caso de la mencionada DGRRDD. Como apuntábamos, ello es debido a la escasa disponibilidad económica, a la importancia que se otorga al componente histórico-artístico de la catedral en tanto que monumento, y a que los daños de mayor gravedad se concentraban principalmente en lo mobiliario más que en lo arquitectónico, que es precisamente el ámbito que vamos a tratar.

14 LÓPEZ GÓMEZ, J.M.: La arquitectura oficial en Teruel durante la era franquista (1940-1960). Teruel, Instituto de Estudios Turolenses, 1988, pág. 56: "implicaba simplemente que el Estado se hacía cargo de la reconstrucción de determinados edificios, de la construcción de los oficiales, la reestructuración urbanística y la concesión de créditos a particulares". 
Por testimonio del arquitecto diocesano sabemos que en 1943 el gobernador civil E. Lamo de Espinosa promovió la idea de terminar la construcción de la catedral, interrumpida desde $1783^{15}$, iniciativa desechada rápidamente ante la magnitud de la empresa y la prioridad por solventar los deterioros que presentaba el monumento ${ }^{16}$. Sin embargo, el primer proyecto desarrollado desde la DGBBAA, fechado en febrero de 1942, no va dirigido propiamente a la reparación de tales daños más que indirectamente. Se trata de la ampliación de la plataforma elevada del presbiterio ${ }^{17}$ : su diseño y realización se deben a Enrique Atencia Molina en su condición de arquitecto diocesano ${ }^{18}$. La memoria del proyecto contiene una sinopsis de la historia del altar mayor de la catedral entre los siglos XVI y XX, relatando los diferentes retablos y altares que fueron proyectados sucesivamente para este lugar hasta alcanzar su configuración definitiva con la realización del tabernáculo diseñado en 1851 por F. Enríquez Ferrer ${ }^{19}$, refiriendo las principales fuentes documentales -literarias y gráficas- para el conocimiento de la historia de este sector de la catedral.

La necesidad de reforma para lograr la ampliación del presbiterio que se persigue está motivada por las reducidas dimensiones con las que se juzga fue diseñado originalmente, y aunque se alega que al parecer su espacio siempre resultó insuficiente para las grandes celebraciones, la carencia real o subjetiva y el interés por resolverla en este momento resultan particularmente significativas del deseo por logar un escenario adecuado, en plena correspondencia con los parámetros y actitudes propias del Nacionalcatolicismo y de su contexto histórico e ideológico.

Lo cierto es que ya antes de 1936 su superficie había sido ligeramente acrecentada con carácter provisional mediante un entarimado lignario soportado por elementos también de madera, el cual, si bien permitía un mayor desahogo, desmerecía a la vista y naturaleza del conjunto: habiendo sido destruida esta ampliación dada su escasa solidez material- durante la mencionada ocupación del edificio por los refugiados de guerra, y una vez restablecidos los cargos eclesiásticos que habrán de participar en las ceremonias propias de la catedral, se pretende recupe-

\footnotetext{
15 PÉREZ DEL CAMPO, L.: Arte y economía: la construcción de la Catedral de Málaga. Málaga, Universidad y $C^{\circ}$ de Arquitectos, 1985, pág. 19; SAURET GUERRERO, T. La catedral... op. cit., pág. 108.

16 AHPM: leg. 13915, carp. catedral 93-1.

17 AGA: fondo (03) 115, sig. 26/285, febrero 1942: "Proyecto de ampliación del presbiterio de la santa iglesia catedral de Málaga". La memoria del proyecto se encuentra también depositada en el AHPM: leg. 13935, carp. 4.23 y 4.25

$18 \mathrm{Su}$ nombramiento tiene lugar en 26.11.1942, si bien venía ocupando interinamente el puesto desde la muerte de Fernando Guerrero Strachan (AHPM: leg. 13935, carp. 4.29), su antecesor en el cargo, ocurrida el 1.7.1941 [PRIETO MORENO, J.: "Fernando Guerrero Strachan. Arquitecto", Revista Nacional de Arquitectura $n^{\circ} 13$, enero 1943, págs. 2-12 (2)] y seguirá ocupándolo hasta 1982. Sobre Atencia Molina destaca la monografía de MORENTE DEL MONTE, M.: La arquitectura malagueña del siglo XX: Enrique Atencia Molina, Memoria de Licenciatura inédita, Universidad de Málaga, 1986; además del trabajo de la misma autora "Enrique Atencia Molina: medio siglo de arquitectura malagueña (I)", en Boletín de Arte n 13-14, $1992-$ 1993, pp. 309-333; así como el de VÁZQUEZ ROMERO, A.: Destrucción y restauración del patrimonio arquitectónico malagueño (1931-1975), Memoria de Licenciatura inédita, Universidad de Málaga, 1993.

19 Ver SÁNCHEZ LÓPEZ, J.A.: Historia de una utopía estética: el proyecto de tabernáculo para la Catedral de Málaga. Málaga, Universidad, 1995, págs. 134 y ss.
} 


\section{Q: artículos Javier Ordónez Vergara}

rar también aquella mayor extensión del presbiterio, aunque esta vez planteada como obra definitiva, es decir, mediante una solución análoga pero en este caso de fábrica. Así, el presbiterio elevado va a ver aumentada su superficie, sobre todo en anchura, con dos nuevas alas que se proyectan sobre el centro de los laterales; en la banda ampliada del lado del Evangelio se prevé la colocación del sitial del obispo. También crece hacia el frente, adelantando la escalinata de acceso y las antas que la flanquean hasta casi duplicar el espacio entre el extremo superior de dicha escalinata y la grada del altar, como puede apreciarse mediante el cotejo de los planos de proyecto con las fotografías anteriores a la realización de la obra.

El criterio defendido por el propio arquitecto es que la disposición del altar ampliado (con sus nuevas proporciones, volumen, orientación y estilo) consiga solventar los nuevos requerimientos litúrgicos mediante tales condiciones espaciales sin repercutir negativamente en la conformación y aprecio de la arquitectura de la cabecera de la catedral. Dada la divergencia entre el trazado mixtilíneo del basamento de los pilares y el perfil lineal del presbiterio, así como sus peculiaridades a nivel de material, color y estética, se propone mantener una separación mínima de $60 \mathrm{~cm}$. entre el perímetro de la plataforma y los citados pilares, de manera que se preserve al menos un pequeño pasillo para permitir circunvalarlo y patentizar así la diferencia entre la estructura histórica del alzado del edificio y el nuevo volumen conseguido para el presbiterio. Pretende asimismo que la parte añadida se ajuste en todo al riguroso diseño académico de la obra original a la cual se adosa, con alineaciones totalmente rectas "siguiendo fiel[mente] a lo existente y pensando en la forma que hubiera podido ser resuelta si se hubiese concebido así primitivamente" 20 . En este sentido, se procura que su simplicidad no parezca impostada para no competir en este aspecto con la sencillez de las partes originales a las que se suma la obra nueva, sino consecuencia de la voluntad por lograr la continuidad respecto de aquella, de modo que apenas existan diferencias entre el estado previo y el resultante, de no ser por el aumento de espacio conseguido que es el objetivo de la intervención ${ }^{21}$.

Es decir, el proyecto supone una elaboración pseudohistoricista que asume las líneas maestras del esquema y el estilo original para conjugarlo en ese momento conforme a las necesidades funcionales que se requieren, en un ejercicio puramente academicista heredero del historicismo decimonónico 22 que tan propio resulta de la arquitectura del primer Franquismo ${ }^{23}$, y que desde el punto de vista de las

20 AGA: fondo (03) 115, sig. 26/285, febrero 1942 "Proyecto de ampliación del presbiterio de la santa iglesia catedral de Málaga", memoria, pág. 4.

21 Lo que puede constatarse en la semejanza entre la descripción del presbiterio histórico y la del finalmente resultante tras la intervención. Ver BOLEA Y SINTAS, M.: Descripción histórica que de la Catedral de Málaga hace su Canónigo Doctoral, Málaga, 1894 (ed. facsímil Universidad de Málaga, introd. Rosario Camacho), págs. 310-311.

22 Continuando la estela representada por el tabernáculo de Enríquez Ferrer como "revival renacentista que perseguía la armonía e integración ornamental, plástica e iconográfica del monumento en la cabecera catedralicia", SÁNCHEZ LÓPEZ, J.A.: "Rex martyrum, sol salutis. El palacio cristológico", en ARCOS VON HAARTMAN, E. (dir): Retrato de la gloria. Restauración del altar mayor de la catedral de Málaga. Barcelona, Winterthur, 1999, págs. 35-54 (53). 


\section{Q: artículos Las restauraciones en la Catedral de Málaga...}
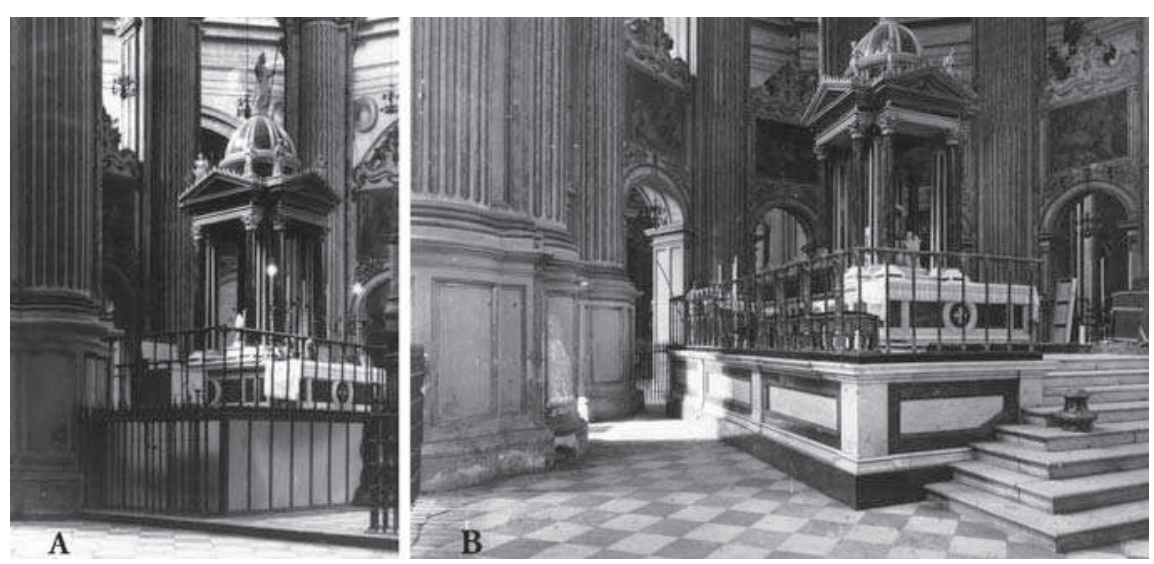

2a. Ampliación provisional del presbiterio, antes de 1936.

2b. Estado previo a la reforma de ampliación de fábrica, en 1942. Ambas imágenes: Archivo General de la Administración (AGA): fondo (03) 115, sig. 26/285.

tendencias en restauración remite a la pretensión violletiana del "acabamiento en estilo", donde no se plantea la necesidad de patentizar un mínimo contraste entre las partes históricas y las producidas por la intervención, sino al contrario: desde la asunción del carácter propio de la obra original y de su naturaleza exclusivamente estética enclavada en un estilo concreto, se realiza un ejercicio de revivalismo que consigue resolver problemas actuales mediante soluciones procedentes del pasado. En esto coincide no solo con la mencionada tendencia de la arquitectura franquista a los estilos históricos ${ }^{24}$, sino también con el proverbial recurso a lo vernáculo y su obligada utilización de materiales y técnicas de construcción tradicionales, propugnando en ocasiones "una arquitectura de retorno a lo falsamente popular" 25.

La memoria se acompaña de varias fotografías correspondientes al primitivo tabernáculo y otros antiguos proyectos (que ilustran la aludida historia del presbiterio), así como de la ampliación anterior a 1936 [2a], tomadas desde varias posiciones (diagonal: [2b]; frontal: [3] para mostrar su fisonomía en el momento previo a la actuación). Además contiene un dibujo [4] en alzado del estado de proyecto "desde

23 UREÑA, G.: Arquitectura y urbanística civil y militar en el período de la autarquía (1936-1945). Análisis, cronología y textos. Madrid, Istmo, 1979, pág. 117.

24 D'ORS, V.: “Hacia la reconstrucción de las ciudades de España”, Vértice, junio 1937.

25 RÁBANOS FACI, C.: "Arquitectura de posguerra en España, ¿qué fue de la modernidad?, en REIG GREEN, M. (ed.): El canto del cisne. Autocrítica de la contracultura. Zaragoza, Universidad, 1985, págs. 189-197 (192). BLANCO, M.: "La arquitectura de Regiones Devastadas", A \& V Monografías 3, 1985, págs. 38-41 (39-40). 


\section{Q: artículos Javier Ordöñez Vergara}

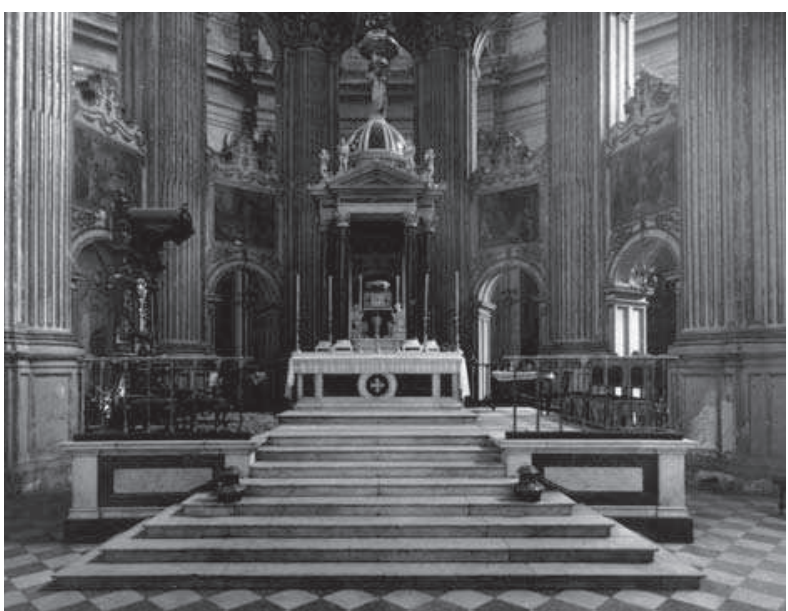

3. Vista frontal del presbiterio anterior a la ampliación de fábrica, en 1942. AGA: fondo (03) 115, sig. 26/285.

el punto de vista más desfavorable", con la futura obra del presbiterio captada tangencialmente desde el lado $\mathrm{N}$ del crucero para demostrar la adecuada resolución del diseño de la ampliación incluso desde esa forzada perspectiva, así como de planos de planta [5], y alzado de varios frentes y de detalle [6].

El proyecto será presentado a la Junta Superior de Monumentos (Ministerio de Educación Nacional) para su aprobación, y si contenía presupuesto éste no se ha conservado en el expediente correspondiente a la obra, depositado en el Archivo General de la Administración. Sí tenemos constancia en cambio de sus condiciones económicas a partir de la documentación contenida en un expediente distinto redactado unos meses más tarde 26 ; por él conocemos algunos aspectos interesantes del procedimiento diseñado para la ejecución material, como el desmontaje del recubrimiento marmóreo de los frentes y de la escalinata, que habían de ser trasladados y montados sobre los nuevos paramentos creados por muros de ladrillo y mortero con $30 \mathrm{~cm}$. de espesor, o la pavimentación de la superficie ganada siguiendo el aspecto de la original. También se informa de los nuevos $10 \mathrm{~m}$. lineales de barandal de bronce y madera necesarios para cerrar la ampliación, lo que da idea del aumento de perímetro obtenido.

Todos estos conceptos de albañilería suponen dos tercios de la inversión prevista, estando destinado el resto a la adquisición e instalación de nuevos materiales de marmolistería: pilastras, molduras, piezas de fondo labradas y nueva mesa de altar, utilizando fundamentalmente piedra de Macael, y de Parchite 27 en menor proporción. La obra sería realizada a partir de 194428 , una vez aprobada 29 por la

26 AGA: fondo (03) 115, sig. 26/285 y 26/286, agosto 1942: "Obras de reforma y conservación en la S.I. Catedral de Málaga". La parte del presupuesto correspondiente a la ampliación del presbiterio asciende a 39.425 '80 pta. de las que 34.890'10 corresponden a ejecución material.

27 Mármol rosado procedente de las canteras próximas a la Estación de La Parchite, pedanía de Ronda. 


\section{2: artículos Las restauraciones en la Catedral de Málaga...}

4. Dibujo a carboncillo del proyecto de ampliación del presbiterio, E. ATENCIA, 1942. AGA: fondo (03) 115, sig. $26 / 285$.

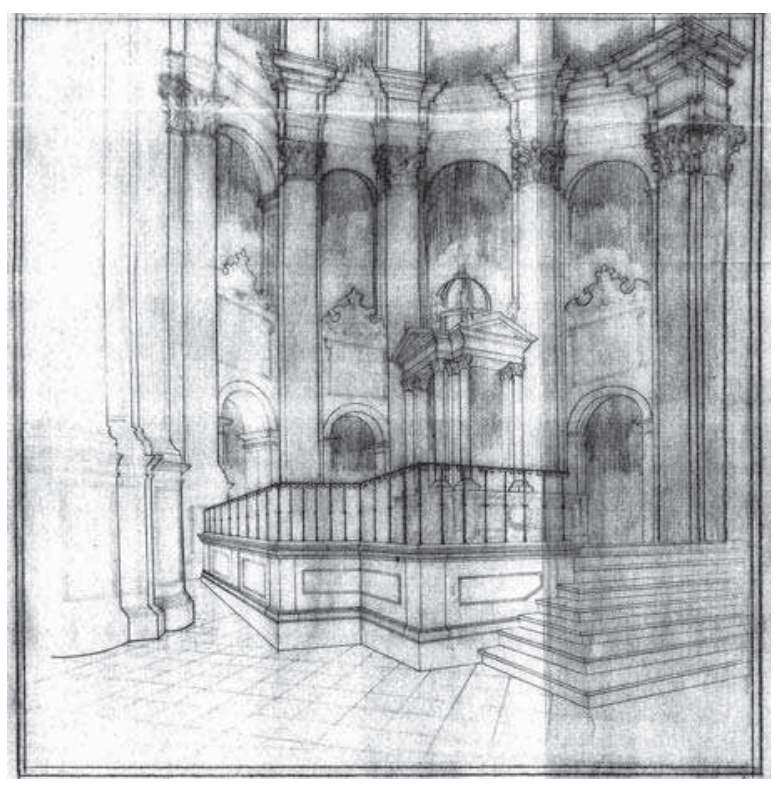

Comisaría General del Servicio de Defensa del Patrimonio Artístico Nacional (DGBBAA), tras el preceptivo informe positivo correspondiente de la Comisión Central de Monumentos ${ }^{30}$. La ponencia ${ }^{31}$, redactada por el arquitecto Antonio Palacios, tan vinculado a Málaga y al propio Atencia, recomendaba sin embargo una pequeña modificación en el diseño de la planta del nuevo presbiterio por el lado de la cabecera, estableciendo un esquema poligonal semejante al de la girola, por el que los ángulos resultantes de la nueva forma de la plataforma elevada habían de apuntar en dirección al eje de los pilares, pero con una separación mínima algo mayor (de $90 \mathrm{~cm}$ ) que la prevista en principio entre dichos ángulos y los pilares; además, la escalinata del trasaltar debía está dispuesta en eje con el vano central de la arquería que cierra por ese lado el presbiterio, y no en paralelo a dicho frente.

Por otra parte, el informe considera adecuada la escasa magnitud de la obra imprescindible para la reforma y se valora que ésta se mantenga exenta respecto a

28 AHPM: leg. 13915, carp. catedral 93-1, y leg. 13935, carp. 5. Esta noticia es contradictoria con otra de 2.2.1943 por la que el arquitecto comunica al obispo el gasto "en la reforma y ampliación del presbiterio" de una cantidad similar a la presupuestada, AHPM: leg. 13915, carp. 2. Podría tratarse de una primera fase.

29 Según comunicación del director general de Bellas Artes, Juan de Contreras, Marqués de Lozoya, al obispo en 10.08.1944. AHPM: leg. 13935, carp. 4.23; y carp. 5, "Datos históricos sobre el origen, construcción y estilo de la S.I. Catedral de Málaga", pág. 18.

30 Real Academia de Bellas Artes de S. Fernando, sesión de 26.06.1944. AHPM: leg. 13935, carp. 4.23

31 AHPM: leg. 13935, carp. 5, "Datos históricos sobre el origen, construcción y estilo de la S.I. Catedral de Málaga", pág. 18 


\section{Q: artículos Javier Ordóñez Vergara}
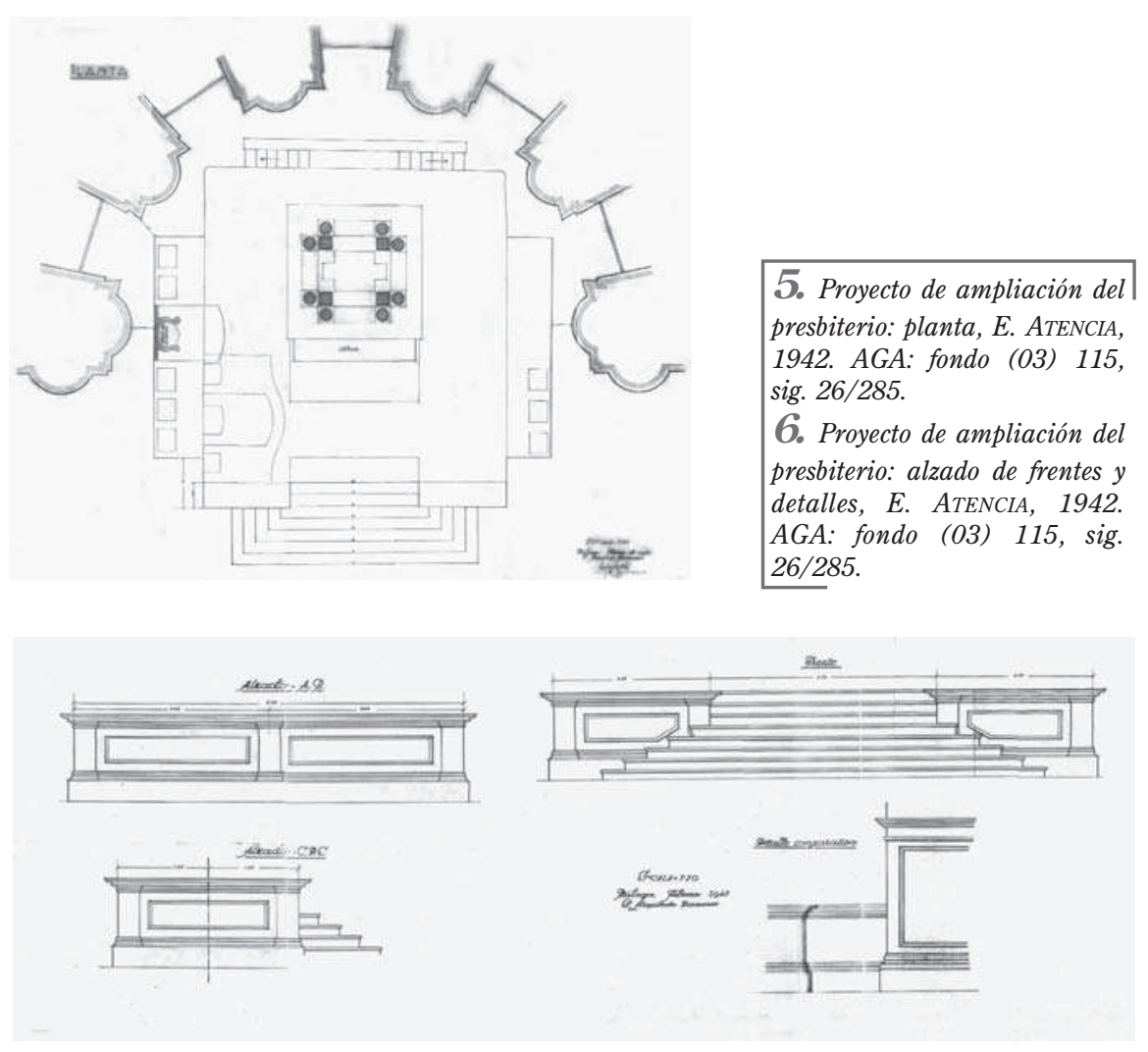

los pilares tal y como se ha indicado, así como que su diseño artístico esté en armonía con el tabernáculo y la arquitectura de la capilla mayor, algo que se logra mediante la modificación del nuevo perfil resultante, y con el hecho de que la nueva fábrica se paramente fundamentalmente haciendo uso de las piezas obtenidas en el desmontaje del enfundado marmóreo de la obra original que desde entonces quedará oculta, de modo "que dicha reforma pasará absolutamente inadvertida" debido a su total ajuste con lo preexistente. En realidad, las únicas objeciones no despejadas por parte de la Comisión (que no son obstáculo sin embargo para su aprobación) se plantean en relación al riesgo de que una obra de ésta o similar naturaleza pudiera servir de precedente a un futuro desmontaje y traslado del coro, como había sucedido entre otros casos españoles- con el de la cercana catedral de Granada pocos años antes; dicha posibilidad, pretendida por algunos, fue finalmente desechada 32 .

32 A la que el propio E. Atencia se mostraba contrario. Supra cit., pág. 19. 


\section{- artículos Las restauraciones en la Catedral de Málaga...}

Finalmente el proyecto se ejecutaría conforme al proyecto original, sin atender a las recomendaciones de la Comisión. Décadas más tarde, presbiterio y altar mayor serían otra vez reformados a partir de mayo de 197433, como adaptación permanente a los usos litúrgicos postconciliares, y nuevamente se realizarían obras en $1987^{34}$. En la actualidad y salvo en el lado del trasaltar, los frentes del podio se encuentran ocultos a la vista por una estructura liviana y reversible que permite al presbiterio extenderse prácticamente por toda la superficie de la capilla mayor; por razones interpretativas se ha instalado en sus inmediaciones una réplica a escala 1:1 de un fragmento del paño marmóreo que ilustra el aspecto de los frentes de la plataforma que hoy se encuentran cubiertos, como modo de permitir al visitante hacerse una idea de su aspecto real.

En el anteriormente referido expediente de agosto de 1942 donde se concretaba la intervención para ampliar el presbiterio, se proyectan además otras dos obras de restauración en diferentes sectores la catedral. Una va dirigida a combatir diversos daños que afectan a la estructura edificatoria y a algunos de sus aditamentos, como las humedades y goteras que presentaban las capillas laterales, sin duda el principal problema de conservación del monumento a lo largo de su historia35. Para ello se prevé actuar en sus terrazas, levantando el solado cerámico y extendiendo una capa de mortero impermeabilizante, para volverlas a cubrir después con una hilada de ladrillo; así como en las verjas -tanto las exteriores como las interiores que cierran las capillas- que aún se hallaban bastante desvencijadas desde la guerra. También se quiere consolidar la cornisa principal de fachada (suponemos que se refiere a la occidental), la cual, debido a la descomposición de la piedra, amenaza con desprenderse en varios puntos no precisados. Por último, se plantea además la renovación parcial de la solería marmórea en las naves y algunas de las capillas. Su presupuesto $^{36}$ se reparte al $50 \%$ entre el primer concepto y el resto.

La otra intervención proyectada entonces proponía reparar algunas de las vidrieras, tanto las que iluminan las naves laterales como las que se localizan en las capillas ${ }^{37}$, reponiendo los elementos desprendidos principalmente a causa del bombardeo italiano de $1937^{38}$. Aunque nada se menciona al respecto en la memoria ni

33 AHPM: leg. 13915, carp. catedral 93-1.

34 AHPM: leg. 13915, carp. 2.

35 LLORDÉN, A.: Historia de la construcción de la Catedral de Málaga. Málaga, Colegio Oficial de Aparejadores y Arquitectos Técnicos, 1988, pp. 301-302, refiere la gravedad de la situación ya en 1859, cuando se encargó un reconocimiento técnico del problema para tratar de darle solución.

3625.750 pta. de ejecución material.

37 Acerca de las mismas ver HUERTAS MAMELY, A.: "Vidrieras de la Catedral de Málaga", en SAURET GUERRERO, T. (dir): Patrimonio cultural de Málaga y su provincia, Edad Moderna. Arquitectura y Urbanismo, vol. II. Málaga, Diputación, 2000, pp. 208-211; y SAURET GUERRERO, T. La catedral... op. cit., pág. 109-113.

38 Los trabajos más laboriosos se proyectan en las que representan la "Crucifixión", "Ascensión" y "Pentecostés", con obras menos cuantiosos en la "Última Cena" y en los dos ventanales de las capillas contiguas, y por último mucho más puntuales en la "Coronación-Pilatos-Flagelación", "San Francisco", 


\section{Q: artículos Javier Ordóñez Vergara}

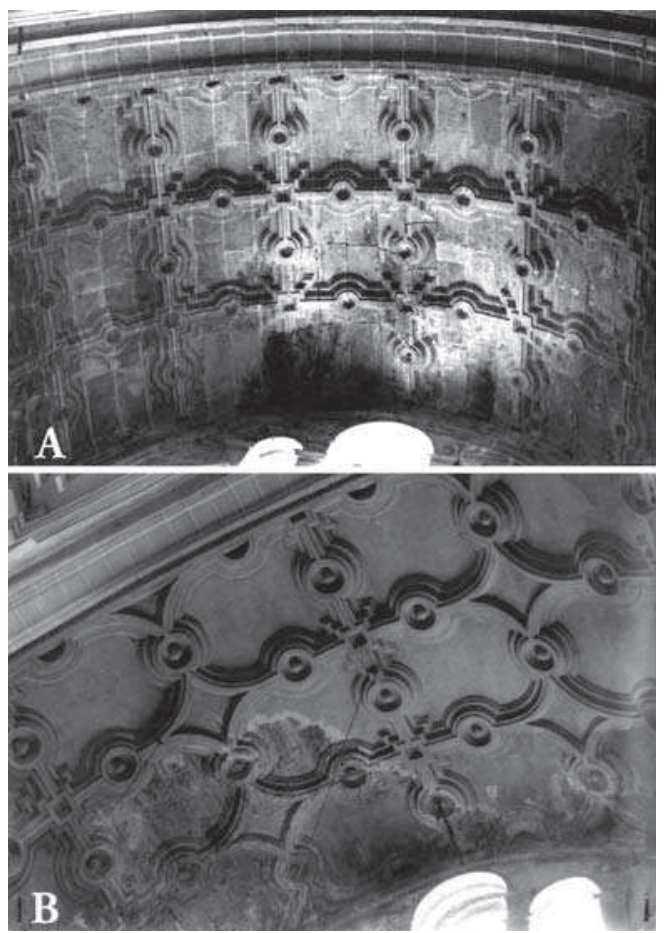

7. Deterioros de las bóvedas de las capillas de a) San Sebastián, y b) del Cristo del Amparo, 1944. AGA: fondo (03) 115 , sig. 26/285.

en el presupuesto, a juzgar por el análisis visual de las vidrieras que se proyectó intervenir, el criterio fue el de la reproducción mimética de lo faltante, tanto en forma como en color. En cualquier caso, tales reparaciones no atenderían más que a los daños de mayor gravedad, a juzgar por el mal estado que presentaban muchas de ellas y que motivó la redacción de otro proyecto de restauración años después 39

Pero ninguna de estas obras se ejecuta aún. Será necesaria la redacción de un nuevo proyecto en julio de 194440 (en este caso firmado por Francisco PrietoMoreno Pardo, desde la guerra arquitecto conservador de la Alhambra y de monumentos de zona ${ }^{41}$ además de jefe de la Comarcal de Granada -Regiones Devastadas-42 y posteriormente director general de Arquitectura entre 1946 y 196043)

"Presentación", "Entrada en Jerusalén” y "Bodas de Caná". La ejecución material ascenderá a 34.921 pta, y el presupuesto total de los tres proyectos refundidos suma 102.156 ' 80 ptas.

39 AGA: fondo (03) 115, sig. 26/366, Prieto-Moreno, 1963-1964.

40 AGA: fondo (03) 115, sig. 26/285: "Proyecto de reparación de la Santa Iglesia Catedral de Málaga", aprobado en 1945.

41 "Don Francisco Prieto Moreno, nuevo Director general de Arquitectura", Revista Nacional de Arquitectura $\mathrm{n}^{\circ} 51$, marzo 1946 , pág. 3.

42 Arriba 17.03.46, "Francisco Prieto Moreno", Reconstrucción n 61, marzo 1946, págs. 88. 
para la reparación de las bóvedas de las capillas del Cristo del Amparo, S. Sebastián, Sta. Bárbara y la antesacristía, cuyos daños muestra en parte la documentación gráfica [7] contenida en el expediente de restauración.

El procedimiento será sustituir los elementos estructurales descompuestos y protegerlos de futuros daños mediante el recubrimiento del trasdós de las bóvedas con rasillas colocadas sobre las partes dañadas de las cubiertas, para proceder a continuación a restaurar el intradós una vez neutralizada la causa primera del deterioro. Además se prevé una actuación menor sobre los pavimentos, dañados por la humedad y por el vandalismo, así como la consolidación y anclaje con hierro de la cornisa de cantería de la fachada principal, sustituyendo los sillares descompuestos por otros nuevos, e impermeabilizándolo todo mediante su recubrimiento por la cara superior con mortero de cemento. También se contempla la restauración puntual de algunos elementos marmóreos desprendidos de dicha fachada y la reparación de la verja principal, así como la renovación de las canales de plomo y bajantes de zinc del conjunto de las cubiertas debido a su mal estado.

De nuevo en esta ocasión, tampoco se realizaron de inmediato algunas de las obras proyectadas, de modo que la demora y lo acuciante de la necesidad de reparación movieron al arquitecto diocesano a la redacción de una nueva "memoria de obras urgentes" fechada en diciembre de 194744: en ella se informa de la grave descomposición de la piedra provocada por la humedad en una buena parte de las cornisas de fachadas y torres, propiciando la caída de algunos fragmentos sobre el patio del Sagrario. El objetivo será reponer los elementos desprendidos con otros de nueva factura, sustituyendo además las piezas originales que -aún in situ- se encontrasen muy dañadas; en general, se necesitaba reparar todos aquellos sillares que representen algún peligro, especialmente los correspondientes a unos $10 \mathrm{~m}$. lineales de la cornisa situada sobre el cuerpo del primer balcón de la torre N. Para la colocación de todos ellos se decide prescindir de cualquier tipo de grapas metálicas y evitar así en lo posible futuros daños a la piedra, recurriendo a la alternativa de labrar las piezas en forma adovelada para encajarlas en la obra antigua. En el contexto de las capillas, y como obra menor presupuestariamente hablando respecto a la de las cornisas exteriores 45 , se proyecta nuevamente la reparación y corrección no acometida aún de las goteras, restañando las juntas abiertas que presentaban algunas bóvedas.

A juzgar por la sucesión de unos proyectos que periódicamente se redactan con objetivos muy semejantes, se deduce que los daños provocados por las hume-

\footnotetext{
43 GALLEGo BURÍN, F.J.: Epistolario de Leopoldo Torres Balbás a Antonio Gallego Burín. Granada, Universidad y Diputación, 1995, pág. 99: Prieto (1910-1985), figura fundamental en la labores de intervención en el patrimonio monumental durante todo el franquismo, se encargó además de la Cátedra de Jardinería y Paisaje en la E.S. Arquitectura de Madrid.

44 AHPM: leg. 13915, carp. catedral.

45 Representa aproximadamente el $20 \%$ frente al $80 \%$ restante correspondiente a las cornisas, de un total de ca. 100.000 ptas.
} 
dades son generalizados y que el problema se ataja siempre sectorialmente, aunque no es posible concretar más dada la imprecisión de las memorias respecto a las zonas intervenidas en cada actuación, solo aclaradas eventualmente por alguno de los planos contenidos en los expedientes.

La razón fundamental de esta dinámica -al margen del hecho de que se atajan los efectos y no tanto las causas del deterioro- es la falta de dotación económica, que cuando está disponible motiva la presentación de un nuevo proyecto parcial a la medida de la partida correspondiente. Por ejemplo: en abril de 1955 PrietoMoreno, en su condición de arquitecto conservador de monumentos de zona, envía una misiva ${ }^{46}$ a Atencia pidiéndole que señale qué obras es necesario realizar en la catedral para invertir una determinada cantidad consignada al monumento en ese año, a la que el arquitecto diocesano responde con la confección de un nuevo proyecto de reparación 47 tanto de las cubiertas como de las cornisas, el cual serviría a Prieto-Moreno para la redacción del suyo, fechado igualmente en abril de 195548; algo más detallado que los habituales de Atencia, se precisan en él las causas del estancamiento de las aguas pluviales en la fábrica y se ofrecen indicaciones concretas acerca de cómo proceder para solventarlas. Por el presupuesto 49 y la documentación gráfica50[8] sabemos que se trata de las bóvedas de la sacristía mayor y del tercer tramo de la nave de la Epístola inmediato a la capilla del Rosario, así como del cornisamiento de la sección $\mathrm{N}$ de la torre del reloj.

Al proyecto seguirán otros en años sucesivos, tanto de Atencia ${ }^{51}$ como de Prieto-Moreno, entre los que destaca el redactado por el arquitecto granadino en marzo de 195652 para las bóvedas del primer tramo de la nave de la Epístola y la capilla de los Caídos [9], así como para zonas indeterminadas de las cornisas exteriores.

Toda esta serie de obras de restauración se compaginan con otras cuya naturaleza, como la mencionada del presbiterio, no es propiamente de conservación sino de reforma. Por lo que respecta a lo inmueble, también es el caso de la reconstruc-

\footnotetext{
46 Fechada en Madrid en 20.4.1955, con membrete del Ministerio de la Gobernación, porque entonces ejerce desde allí -entre otros cargos- como director general de Arquitectura y comisario de ordenación urbana del Gran Madrid.

47 AHPM: leg. 13915, carp. catedral: "Obras de restauración de la Catedral de Málaga", con presupuesto de 50.000 ptas. fechado en 28.4.1955.

48 AGA: fondo (03) 115, sig. 26/285: "Proyecto de obras de restauración de la Catedral de Málaga", con presupuesto de $49.999,22$ ptas.

49 El $80 \%$ se destina al revestido exterior de las bóvedas y el resto a la reparación de los daños provocados por la sujeción del barandal de defensa del cornisamiento del primer entablamento de la torre del reloj.

50 AGA: fondo (03) 115, sig. 26/285: "Proyecto de obras de restauración de la Catedral de Málaga", "Planta. Mayo 1955". Se utiliza como base un calco de la planta dibujada por A. Ramos y grabada por Muntaner en 1784.

51 AHPM: leg. 13915, carp. catedral. A la subvención para la mencionada obra concedida en 1955 por la Dirección General de Asuntos Eclesiásticos -luego Religiosos-, siguió otra en 1956. En el mismo 1955 el propio Ministerio de Justicia -de quien depende la citada DGAAEE- concedió una subvención de 180.000 ptas. con las que Atencia programa obras para solventar problemas en bóvedas, muros, escaleras y torres con un presupuesto de 162.550 ptas. fechado en 7.1.1956.

52 AGA: fondo (03) 115, sig. 26/285: "Proyecto de obras de restauración de la Catedral de Málaga", marzo
} de 1956 , presupuesto de $49.994,39$ ptas. Aprobado en 19.6.1956. 


\section{2: artículos Las restauraciones en la Catedral de Málaga...}
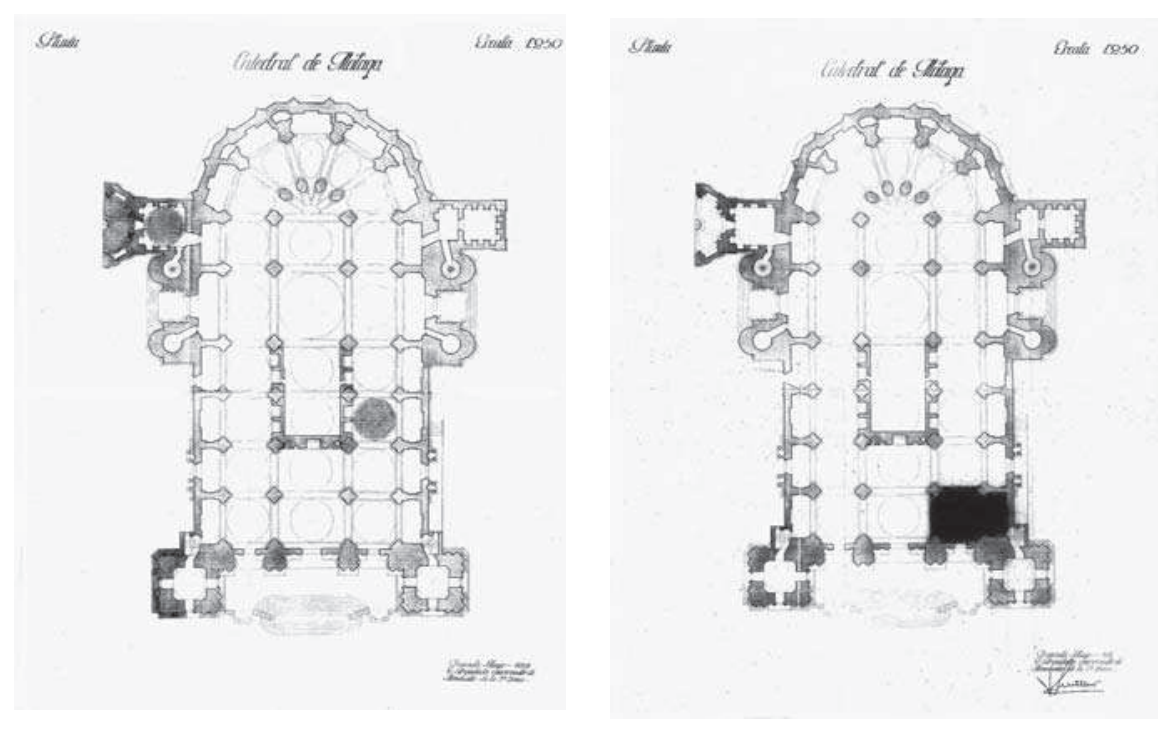

8. Planta con indicación de los sectores de cubiertas y cornisas a restaurar, F. PRIETO-MORENO, 1955. AGA: fondo (03) 115, sig. 26/285.

9. Planta con indicación del sector de cubiertas a restaurar, F. PRIETO-MORENO, 1956. AGA: fondo (03) 115, sig. 26/285.

ción y remodelación de la capilla del Sagrado Corazón de Jesús ${ }^{53}$, segunda del lado de la Epístola, o de la primera de este mismo lateral para disponer en ella los restos de víctimas de la guerra civil ${ }^{54}$ que habían sido trasladados a la catedral en 1941 , los cuales serán depositados en la entonces denominada capilla 'de la Victoria' y más tarde 'de los Caídos'. El proyecto fechado en junio de $1946^{55}$ contempla la excavación de la cripta, con sus correspondientes muros y forjado de cubierta, la pavimentación marmórea análoga a la del resto de la catedral y la decoración centrada en el montaje de las vidrieras ${ }^{56}$ representando a la Virgen de la Victoria entre los arcángeles S. Miguel y S. Rafael, en referencia a los cementerios de la ciudad, a la

53 AHPM: leg. 13935, carp. 4.4: certificación del gasto de 16.087,09 ptas. en concepto de obras en el abovedado del piso, pavimento y zócalo marmóreo, mayo de 1945.

54 MATEO AVILÉS, E. de: Las víctimas... op. cit., págs. 38 y 109-116. Sus prolegómenos se remontan a 1937, cuando se constituye la comisión pro-víctimas del marxismo, ver BARRANQUERO TEXEIRA, E.: Málaga entre... op. cit., págs. 146 y ss.

55 AHPM, leg. 13915, carp. catedral: "Presupuesto de reconstrucción de una capilla de la S. I. Catedral de Málaga dedicada a los mártires de nuestra cruzada de liberación”.

56 El presupuesto, de $42.288,82$ pta, se asigna a partes aproximadamente iguales a estos tres conceptos. 


\section{Q: artículos Javier Ordónez Vergara}

que se añadirá el retablo de Navas Parejo 57 al que no se hace referencia en el proyecto de Atencia. La capilla no adquiriría su aspecto definitivo hasta 1965.

\section{AVANCE DE CONCLUSIONES.}

En el ámbito de la catedral propiamente dicha, la combinación de reformas que podemos considerar funcionales (aunque no exentas de una indudable carga simbólico-ideológica) con otras de conservación en sentido estricto, parece mostrar el deseo de armonizar mediante los escasos medios disponibles la continuidad de la integridad monumental del edificio con la mejora -entendida como adaptación- a los nuevos requerimientos que se plantean, fruto de su particular contexto histórico.

Por otro lado, tanto unas (reformas) como otras (intervenciones de reparación y conservación), están fuertemente determinadas por las siempre escasas posibilidades económicas con las que se sufragan. Ello impide que cualquier objetivo pueda ser enfocado desde un planteamiento global, sistemático y a largo plazo, como estrategia -pretendidamente al menos- "definitiva"; por el contrario, la urgencia por atajar requerimientos muchas veces complejos y diversos obliga a tener que solventarlos casi siempre de forma lenta, facetada y consecutiva, prerrelacionando las necesidades en cada actuación conforme al grado de urgencia que se les diagnostica, cumpliendo los objetivos solo parcialmente hasta agotar la dotación económica disponible en cada momento, que siempre se impone a la exigencia real por ejecutar con diligencia unas reparaciones que generalmente resultan menos extensas y profundas de lo que debieran.

En cuanto a las implicaciones propiamente artísticas de estas intervenciones, puede decirse que -grosso modo- apenas se plantean, y cuando lo hacen es de modo muy secundario frente a la mayor atención que exigen las vertientes material y funcional del edificio. No obstante, habrá que matizar esta idea cuando se analicen las intervenciones realizadas en otros sectores del conjunto catedralicio, mucho más interesantes a nuestro juicio y donde el componente artístico cobrará mayor protagonismo por diversas causas.

57 CAMACHO MARTíNEZ, R. (dir.): Guía histórico-artística de Málaga. Málaga, Arguval, 2006, págs. 127-128. 